\title{
Postural Behavior in Children Born Preterm
}

\author{
Bjørg Fallang ${ }^{1}$ and Mijna Hadders-Algra ${ }^{2}$ \\ 'Oslo University College, Health Sciences, Physiotherapy Programme, 0130 Oslo, Norway; \\ ${ }^{2}$ University Hospital Groningen, Department of Neurology, Groningen, The Netherlands
}

\section{SUMMARY}

The present paper presents clinical and neurophysiological data of postural behavior in preterm children without CP. Clinical followup studies of preterm infants until toddler and school age have reported that low-risk preterm infants may have atypical postural behavior in terms of reduced amount of rotation during crawling, delayed dynamic balance, delayed onset of and a poor quality of early walking behavior. At school age, dysfunctions such as problems in standing on one leg and poor hopping are reported. Neurophysiological data of postural control at early age indicated the presence of a dysfunction in the capacity to modulate postural activity, and the postural activity has been characterized by temporal disorganization of EMG responses. Postural responses to goal-directed reaching in supine lying have been recorded and analyzed in terms of the total body center of pressure. In this study, preterm infants show less mobile postural behavior compared with full-term infants. In infancy, the less mobile postural behavior seemed to be adequate as it was related to better goal-directed reaching quality, but the results indicated that the relatively immobile postural behavior during reaching in early age was related to less favorable neuromotor behavior in school-age.

Reprint requests to: Bjørg Fallang, Oslo University College, Health Sciences, Postbox 4, St. Olavs Place, 0130 Oslo, Norway; e-mail bjorg.fallang@hf.hio.no

\section{INTRODUCTION}

Preterm birth challenges the development of motor control not only because of an increased risk of periventricular hemorrhage and leukomalacia but also because the infant starts extrauterine life with an immature and more vulnerable motor and sensory system. As a result, one of the frequently occurring sequelae of preterm birth is a lack of adequate postural control during motor activities. This occurs not only in children with cerebral palsy (CP) but also in those without $\mathrm{CP}$. In the present paper, we aim at discussing the clinical and neurophysiological data of postural behavior in preterm children without $\mathrm{CP}$.

\section{CLINICAL DATA ON POSTURAL BEHAVIOR IN PRETERM CHILDREN}

In early infancy, deviations in the postural behavior of preterm infants have been described as transient dystonia, a postural behavior reminiscent of postures exhibited during the dystonic stage of diplegia. This means that the infants may show brisk tendon reflexes and when held in the vertical position, extended and adducted legs with plantiflexed feet, rigid arms with fisted hands, while head control depends on body position (Drillien. 1972). De Groot and colleagues (1992) described the postural behavior of preterm infants in terms of faulty muscle power, defined as an imbalance between the active adjustments to changes in posture and passive muscle tone. Excess of extension behavior has also been reported as 
"fixing behavior" with extremities to the support surface (Gorga et al., 1985), and as extension and shoulder retraction in sitting (Georgieff et al., 1986). The incidence of transient dystonia or faulty muscle power in children who do not develop cerebral palsy has been reported to be between 28 percent (Sommerfelt et al., 1996) and 40 percent (de Groot et al., 1995).

Follow-up studies of preterm infants into toddler and school age have reported that even low-risk preterm infants may have dysfunctions in postural control; for instance they show a reduced amount of rotation during crawling, delayed dynamic balance, delayed onset of independent walking, and a poor quality of early walking behavior (Gorga et al., 1988; de Groot et al., 1995, 1997; Bylund et al., 1998). At school age, dysfunctions in balance control are expressed as problems in standing on one leg (Forslund \& Bjerre, 1989; Marlow et al., 1989; Herrgård et al., 1993), poor hopping, and clumsy walking (Sommerfelt et al., 1993). The relationship between the early deviations in postural muscle power regulation (at 4 months) and development during the first year of life has been addressed by the group of de Groot in both low- and high-risk preterm infants. In low-risk preterm infants, early postural dysregulation has been associated with poorer sitting performance, asymmetries (de Groot et al., 1995, 1997) and non-optimal hand functions (Plantinga et al., 1997) at 9 months of age. In highrisk preterm infants, early muscle dysregulation and dysfunctional postural behavior at 12 months were the best predictors for neurodevelopmental outcome at 7 years of age (Samsom et al., 2002). When de Vries and de Groot (2002) re-examined a selected low-risk sample of these preterm infants, however, the authors were unable to confirm a relationship between muscle dysregulation at 4 months and motor performance in terms of trunk rotation at 2.6 years. In a study with preterm infants without cerebral palsy, Sommerfelt et al. (1996) reported a trend toward more neuromotor problems at 5 years in children with early transient dystonia. Therefore, how these early deviations in postural behavior are related to the postural deviations described at school age is not clear. Although, the implications are still uncertain, dystonia might be an important trait in early behavior and should probably be included in the evaluation of low-risk infants. Insight into the emergence and nature of these problems is important in order to know when and how therapeutic interventions might be introduced.

\section{NEUROPHYSIOLOGICAL DATA ON POSTURAL BEHAVIOR IN PRETERM CHILDREN}

In studies for which EMG recordings have been applied, postural muscle activity of preterm children differs from that of full-terms. One study (Hadders-Algra et al., 1999) evaluated postural activity in response to platform perturbations in sitting children aged $1 \frac{1}{2}$ to $4 \frac{1}{2}$ years. The authors reported that preterm children with periventricular white matter lesions and those with normal ultrasound scans were less able to modulate postural muscle activity to initial sitting position. As the preterm children also showed an increased sensitivity to velocity dependent stretch, it was suggested that in preterm children, the normal balance between feedforward and feedback control of posture has been replaced by a form of control during which feedback processes dominate.

The longitudinal study of van der Fits et al. (1999), in which postural muscle activity during reaching in various positions of full-term and preterm infants was assessed between the ages of 3 and 18 months, confirmed the presence of a dysfunction in the capacity to modulate postural activity. The study also showed that preterm infants older than 4 months activated more postural muscles during reaching than full-term infants did, and that the postural adjustments of preterm infants were characterized by temporal disorganization. 
Recently we carried out a small series of studies on qualitative and quantitative aspects of postural behavior at 4 and 6 months corrected age in 12 fullterm (Fallang et al., 2000) and 32 preterm infants who did not develop cerebral palsy (Fallang et al., $2003 \mathrm{~b}$ ). The preterms were divided into two groups, 11 infants were allocated to a high-risk group (mean gestational age 28 weeks) if they had either one or more of the following problems: Apgar score less than 3 at 5 minutes, respiratory problems, or a persistent ductus arteriosus. Twenty-one low-risk preterms were without these problems (mean gestational age 30 weeks). The infants were placed in a supine position on a forceplate, with an attractive toy above them to reach for. The forceplate below the infant recorded the postural adjustments during the reach. The movement of the total body center of pressure (COP) was analyzed in terms of total travel path and maximum velocity in both cranial-caudal and medial-lateral direction. In addition to the forceplate data, kinematic data of the reaching movement were collected. The kinematics of the reaching hand was analyzed in terms of peaks in the velocity profile called movement units (MU). Earlier analysis of MUs in full-term infants revealed that reaching movements in general become more straight-lined and exhibit fewer corrections in the movement path with increasing age (von Hofsten, 1982, Thelen et al., 1993).

We found that the total body COP of preterm infants differed markedly from that of full terms. The preterm infants showed a relatively immobile postural behavior, i.e. a very small travel path of COP, during reaching compared with full-term infants at both 4 (Fig. 1a) and 6 months (Fig. 1b), whereas no differences were found between the low-risk and high-risk preterms. In addition, the maximum velocity of COP of preterm infants was substantially lower than that of full-term infants at both testing ages. Two additional differences in postural control were found between full-term and preterm infants in relation to direction and to age.
The full-term infants showed more COP movements in medial-lateral direction than in cranial-caudal direction, and the size of the COP movements decreased with age in full-term infants, whereas no directional or age-related changes were found in the preterm infants (Fig. la,b). The differences in postural behavior between full-term and preterm infants could not be explained by differences in anthropometrics. The only perinatal parameter in preterm infants associated with postural behavior was gestational age at birth, whereas no relation between postural behavior and perinatal parameters like birthweight, respiratory morbidity, or ultrasound scans of the neonatal brain or sex was found.

We wondered whether the different postural behavior of preterm infants was a sign of neural dysfunction or could be regarded as a functional adaptation of the infant in response to the early extrauterine environment. Arguments in favor of the latter view were that the less mobile total body movement during reaching at 6 months was associated with better quality of reaching, a higher gestational age at birth (above 28 weeks), and with the presence of normal general movements at 4 months (Figs. 2 and 3). In general a higher gestational age is associated with a lower rate of neurodevelopmental morbidity (Allen, 2002), and normal general movements point to the integrity of the function of the central nervous system (Hadders-Algra, 2004). At 4 months of age, less mobile COP behavior was associated with shorter duration of the reach and less number of movement units, at 6 months it was related to reaching movements characterized by medium velocity with few movement units (Fallang et al. 2003a,b). We therefore concluded that at early age, the relatively immobile postural behavior during reaching might be considered a functional adaptation. Nevertheless, we wondered whether the atypical and at early age adaptive postural behavior of preterm infants could be a marker of later dysfunction as well. 

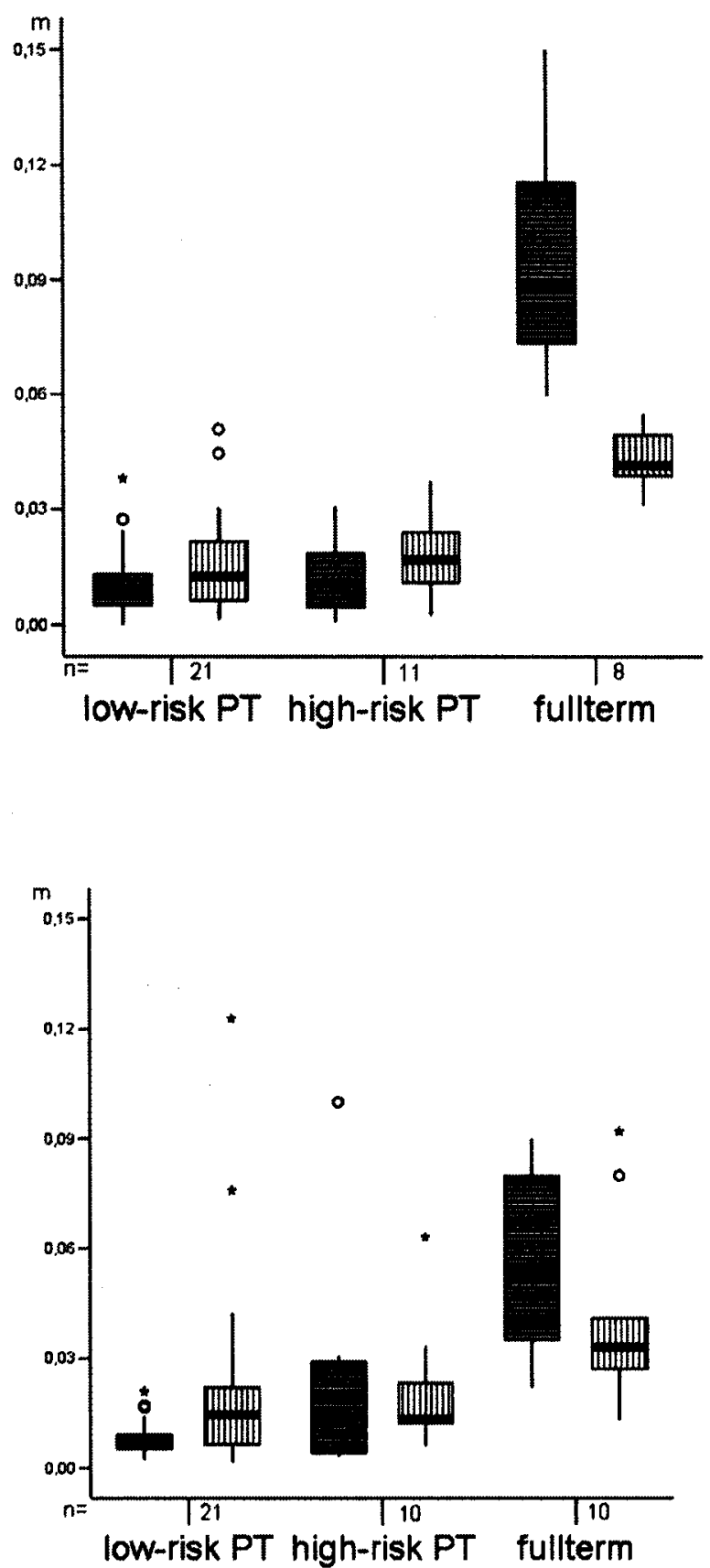

Fig. 1: (adapted from Fallang et al. 2003). Displacement in both the medial-lateral (horizontally lined boxes) and cranial-caudal (vertically lined boxes) directions are smaller in both low-risk and high-risk preterm infants compared to full-term infants, at 4 months (panel a; $p<0.001$ ) and at 6 months (panel b; difference between fullterm and preterm infants in medial-lateral direction $p<0.01$, rest of comparisons: $p<0.05$ ) 




Fig. 2: COP displacement at 6 months and its relation to quality of General Movements (GMs) at 4 months in preterm infants. Difference between normal and mildly abnormal GMs: $p<0.05$

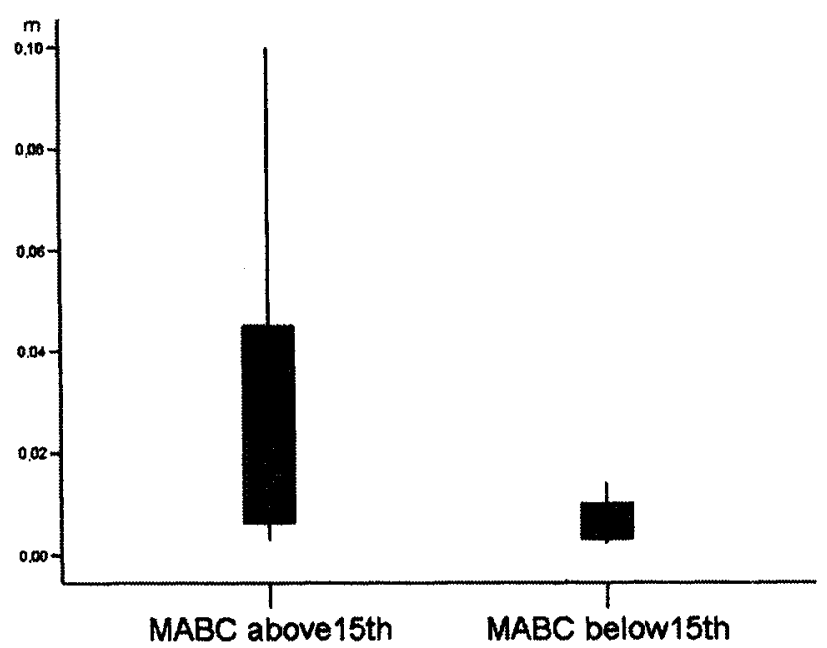

Fig. 3: The relationship between displacement of COP in medial-lateral direction at 6 months of age and Movement $\mathrm{ABC}(\mathrm{MABC})$ scores above and below the $15^{\text {th }}$ percentile at school-age in preterm and full-term children. Difference between two Movement $A B C$ groups: $p<0.01$. 


\section{RELATIONSHIP BETWEEN COP AT EARLY AGE AND NEUROMOTOR BEHAVIOR AT SCHOOL-AGE}

To understand the implications of our earlier findings of the relatively immobile postural behavior in preterm infancy, we also did a followup study on these children to elaborate on possible associations between this early postural behavior and neuromotor behavior at school-age. ${ }^{1}$ Fifty-two preterm children were available for follow-up at 6 years of age. They were assessed with Movement ABC (Henderson \& Sugden, 1992) and Touwen's (1979) neurological assessment. The objective of Movement $\mathrm{ABC}$ is to identify children with motor problems in the three subsections: manual dexterity, ball skills, and balance skills. The assessment is widely used (Geuze et al., 2001). The total score can be converted to a percentile score, reflecting the child's score compared to a normative sample. A percentile ranking above $15^{\text {th }}$ is considered normal, between $5^{\text {th }}$ and $15^{\text {th }}$ is in the borderline range, and below $5^{\text {th }}$ percentile the child is considered as having problems. Touwen's (1979) neurological assessment is a standardized neurological assessment constructed to detect minor neurological abnormalities, which can be classified as simple or complex forms of minor neurological dysfunction (MND). Simple MND reflects the presence of a normal but non-optimally wired brain, which can be attributed to genetic constitution, or to stressful events during early life such as preterm birth. Complex MND can be considered a clinically significant brain dysfunction (Hadders-Algra, 2003).

Our hypothesis that the relatively immobile postural behavior during reaching at an early age could be an adequate functional adaptation to extra-uterine demands did not seem to hold true for neuromotor behavior at school age. The results

\footnotetext{
' Fallang et al. Quality of reaching and postural control in young preterm infants is related to neuromotor outcome at 6 years. Pediatr Res (accepted for publication).
}

indicated that the relatively immobile postural behavior during reaching in early age was related to less favorable neuromotor behavior in school age, e.g. this postural behavior at 4 months was associated with simple MND ( $p<0.05$, grouped full-term and preterm). The postural behavior at 6 months was associated with a worse score on the Movement ABC $(p<0.01$, grouped full-term and preterm; Fig. 3). This finding suggests that this relatively immobile postural behavior points to a mild form of brain dysfunction. When we analyzed the associations between COP behavior and subscores of Movement $\mathrm{ABC}$, we found that worse scores on balance skills were related to reduced COP movement $(\mathrm{p}<0.01)$, but not to hand motor or ball skills.

\section{CONCLUDING REMARKS}

How can we understand these findings? In preterm infants, reduced postural movement during reaching (Fallang et al., 2003b) might be analogous to the lack of modulation and excessive trunk muscle activity found in EMG studies in response to reaching (van der Fits et al., 1999) and to the observation of "fixing" behavior reported by Gorga and colleagues (1988) and de Groot and coworkers (1997). This may be interpreted as a functional strategy: the infant is freezing degrees of freedom to perform the reaching. On the other hand, this freezing of degrees of freedom may hamper the dynamic, normal exploration and variation of solutions during the process of learning new behavior that are prevailing in normal development (Touwen, 1993), which in this context was to learn successful reaching. Variation in postural muscle activity characterizes the postural behavior of typically developing children in response to perturbation of the support surface (Hirschfeld \& Forssberg, 1994; HaddersAlgra et al., 1996), in response to loosing trunk support (Harbourne \& Mac Neela, 1993), and in 
response to voluntary reaching activity (van der Fits et al., 1999).

What then are the clinical implications? The relatively immobile postural behavior during reaching at early age was not related to clinically significant brain dysfunction in the form of complex minor neurological dysfunction. Such behavior was associated with less optimal motor development, however, which might indicate that preterm infants are at risk of experiencing poor explorative motor behavior and lack of variation in movements. As variation in the movement repertoire seems to be important in normal motor behavior (Hadders-Algra, 2000) we have to pay attention to this aspect of development. When early intervention is applied, we should therefore warrant and stimulate the infant to explore more motor solutions in the early learning of new behavior. So far, the results from the kinetic studies cannot be directly implemented into clinical use. However, the results from clinical studies by, for example Gorga et al. (1988), de Groot et al. (1997), and Samsom et al. (2002), and the detailed neurophysiological studies of reaching and postural behavior (van der Fits et al., 1999; Fallang et al., 2003a,b), can help in designing new or in improving present clinical instruments or in giving directions for clinical observations. As we extend our knowledge of the minor and moderate motor problems in preterm children, the assessments may be more specifically attuned to the problems in this group.

\section{REFERENCES}

Allen MC. 2002. Preterm outcomes research: a critical component of neonatal intensive care. Ment Retard Dev Disabil Res Rev 8: 221-233.

Bylund B, Cervin T, Finnström $O$, Gäddlin PO, Kernell A, Leijon I, et al. 1998. Morbidity and neurological function of very low birthweight infants from the newborn period to $4 \mathrm{y}$ of age. A prospective study from the south-east region of Sweden. Acta Pædiatr 87: 758-763. de Groot L, Hopkins B, Touwen BC. 1992. A method to assess the development of muscle power in preterm after term age. Neuropediatrics 23: 172179.

de Groot L, Hopkins B, Touwen B. 1995. Muscle power, sitting unsupported and trunk rotation in preterm infants. Early Hum Dev 4: 337-346.

de Groot L, Hopkins B, Touwen B. 1997. Motor asymmetries in preterm infants at 18 weeks corrected age and outcomes at 1 year. Early Hum Dev 48: 35-46.

Drillien CM. 1972. Abnormal neurological signs in the first year of life in low-birthweight infants: Possible prognostic significance. Dev Med Child Neurol 14: 575-584.

Fallang B, Saugstad OD, Hadders-Algra M. 2000. Goal directed reaching and postural control in supine position in healthy infants. Behav Brain Res 115: 9-18.

Fallang B, Saugstad OD, Grøgaard J, Hadders-Algra M. 2003a. Kinematic quality of reaching movements in preterm infants. Pediatr Res 53: 1-7.

Fallang B, Saugstad OD, Hadders-Algra M. 2003b. Postural adjustments in preterm infants at 4 and 6 months post-term during voluntary reaching in supine position. Pediatr Res 54: 826-833.

Forslund M, Bjerre I. 1989. Follow-up of preterm children I. Neurological assessment at 4 years of age. Early Hum Dev 20: 45-66.

Georgieff MK, Bernbaum JC, Hoffmann-Williamson Daft A. 1986. Abnormal truncal tone as a useful early marker for developmental delay in low birthweight infants. Pediatrics 77: 659-663.

Gueze RH, Jongmans MJ, Schoemaker MM, SmitsEngelsman BC. 2001. Clinical research diagnostic criteria for developmental coordination disorder: a review and discussion. Hum Mov Sci 2001. 20: 7-47.

Gorga D, Stern FM, Ross G. 1985. Trends in neuromotor behavior of preterm and fullterm infants in the first year of life: a preliminary report. Dev Med Child Neurol 27: 756-766.

Gorga D, Stern FM, Ross G, Nagler W. 1988. Neuromotor development of preterm and fullterm infants. Early Hum Dev 18: 137-149.

Hadders-Algra M. 2000. The neuronal group selection theory: a framework to explain variation in normal motor development. Dev Med Child Neurol 42: 566-572.

Hadders-Algra M. 2003. Developmental coordination disorder: is clumsy motor behavior caused by a 
lesion of the brain at early age? Neural Plast 10: 39-50.

Hadders-Algra M. 2004. General movements: a window for early identification of children at high risk of developmental disorders. J Pediatr 145: S12-8.

Hadders-Algra M, Brogren E, Forssberg H. 1996. Ontogeny of postural adjustments during sitting in infancy: variation, selection and modulation. $J$ Physiol 493: 273-288.

Hadders-Algra $M$, Brogren $E$, Katz-Salamon $M$, Forssberg H. 1999. Periventricular leucomalacia and preterm birth have different detrimental effects on postural adjustments. Brain 122: 727-740.

Harbourne RT, Mac Neela CGJ. 1993. A kinematic and electromyographic analysis of the development of sitting posture in infants. Dev Psychobiol 1993. 26: 51-64.

Henderson SE, Sugden DA 1992. Movement Assessment Battery for Children. London, UK: The Psychological Corporation; 1-276.

Herrgard E, Luoma L, Tuppurainen K, Karjalainen S, Martikainen A. 1993. Neurodevelopmental profile at five years of children born at $(<$ or $\Rightarrow$ ) $\leq 32$ weeks gestation. Dev Dev Med Child Neurol 35: 1083-1096.

Hirschfeld H, Forssberg H. 1994. Epigenetic development of postural responses for sitting during infancy Exp Brain Res 97: 528-540.

Hofsten von C. 1982. Eye-hand coordination in the newborn. Dev Psychol 18: 450-461.

Marlow N, Roberts BL, Cooke RW. 1989. Mo tor skills in extremely low birthweight children at the age of 6 years. Arch Dis Child 64: 839-847.
Plantinga Y, Perdoch J, de Groot L. 1997. Hand function in low-risk preterm infants: its relation to muscle power regulation. Dev Med Child Neurol 39: 6-11.

Samson JF, de Groot L, Bezemer PD, Lafeber HN, Fetter WPF. 2002. Muscle power development during the first year of life predicts neuromotor behavior at 7 years in preterm born high-risk infants. Early Hum Dev 68: 103-118.

Sommerfelt K, Ellertsen B, Markestad T. 1993. Personality and behavior in eight-year-old, nonhandicapped children with birth weight under 1500 g. Acta Pædiatr 82: 723-728.

Sommerfelt K, Pedersen P, Ellertsen B, Markestad T. 1996. Transient dystonia in non-handicapped lowbirthweight infants and later neurodevelopment. Acta Paediatr 85: 1445-1449.

Thelen E Corbetta D, Kamm K, Spencer JP, Schneider K Zericke RF. 1993. The transition to reaching: mapping intention to intrinsic dynamics Child Dev 64: 1058-1098.

Touwen BCL. 1979. Examination of the child with minor neurological dysfunction. Clinics in Developmental Medicine No. 71. $2^{\text {nd }}$ ed. London, UK: William Heinemann Medical Books; 123.

Touwen BC. 1993. How normal is variable, or how variable is normal? Early Hum Dev 34: 1-12.

van der Fits I, Hadders-Algra M. 1999. Development of postural adjustments during reaching in preterm infants Pediatr Res 46: 1-7.

Vries de AM, de Groot L. 2002. Transient dystonias revisited: a comparative study of preterm and term children at $2 \frac{1}{2}$ years of age. Dev Med Child Neurol 44: 415-421. 

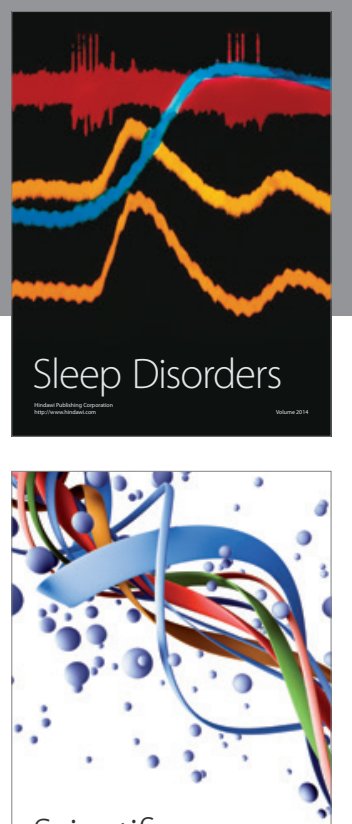

Scientifica
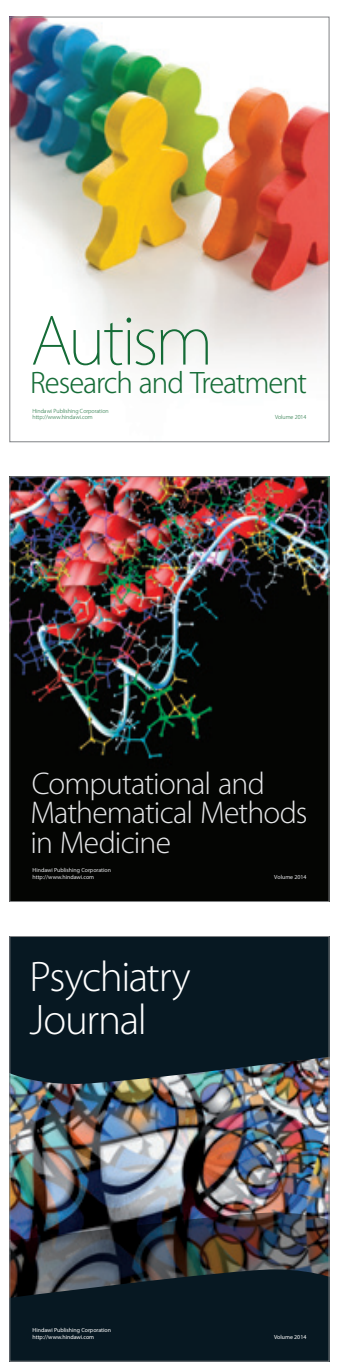
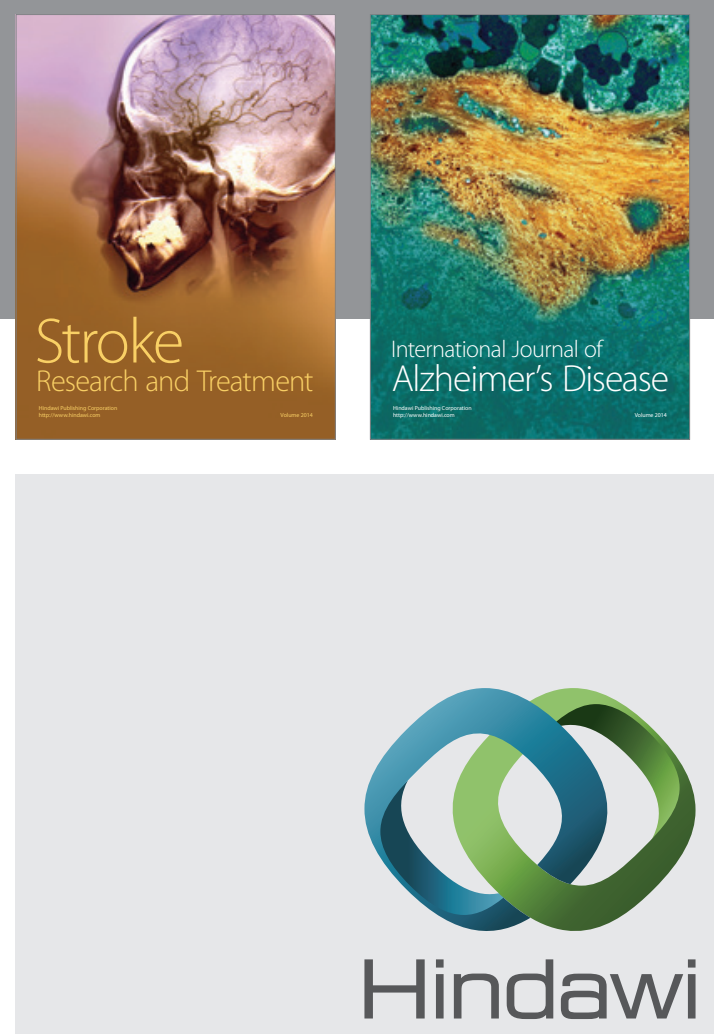

Submit your manuscripts at

http://www.hindawi.com
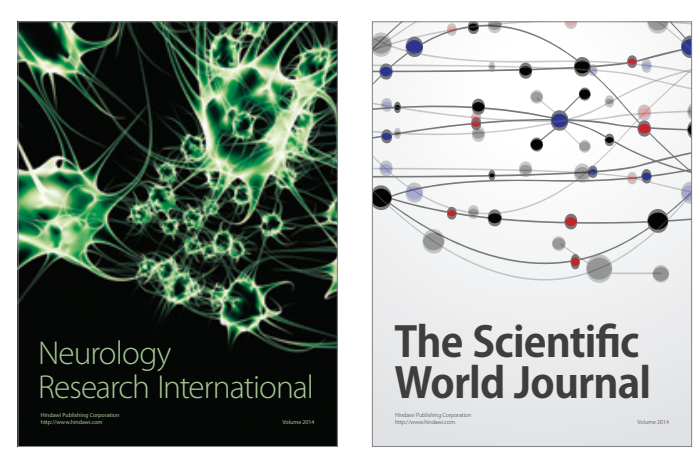

The Scientific World Journal

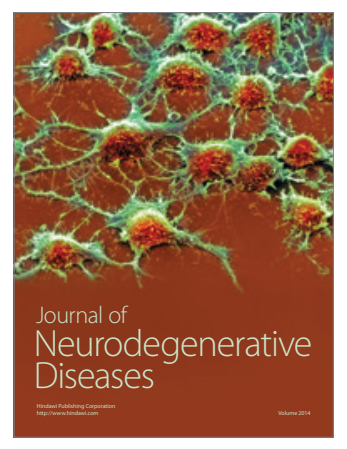

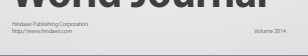

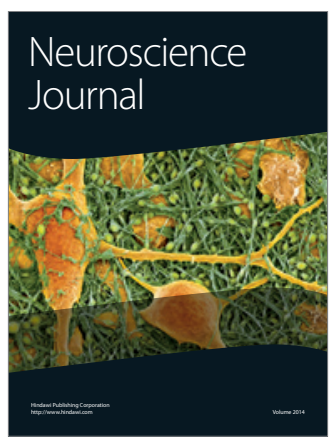

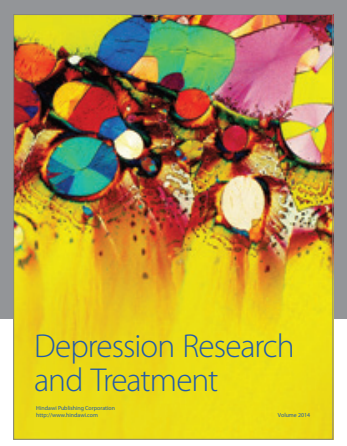
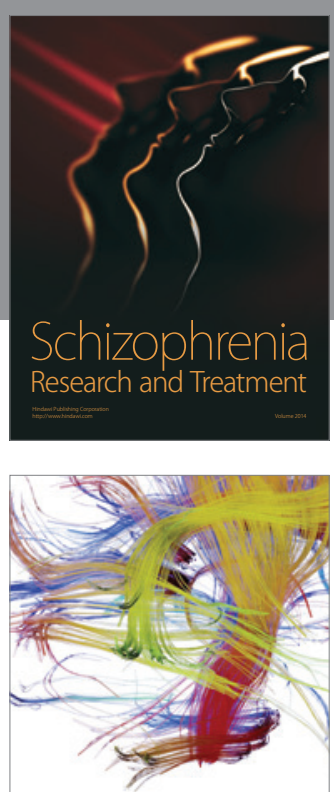

Brain Science

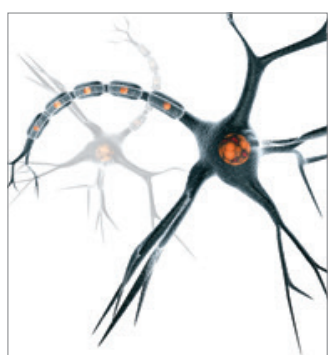

Neural Plasticity
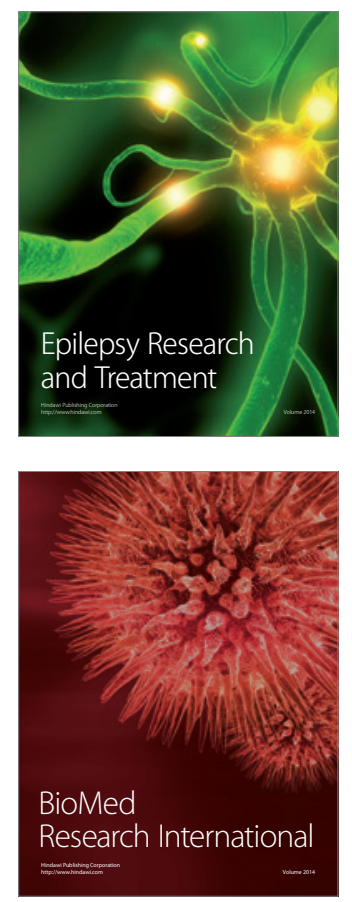

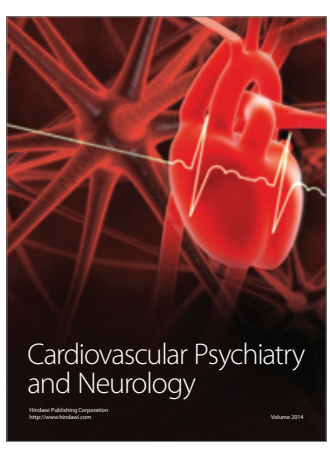

Parkinson's

Disease
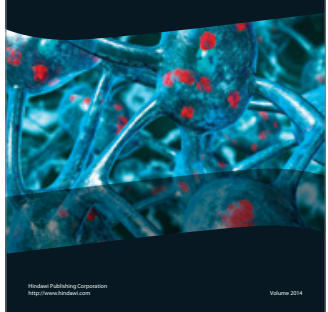